\title{
Gestão e qualidade da educação escolar básica: sentidos em construção
}

\author{
Management and quality of basic education: meanings under construction
}

\author{
Graziela Zambão Abdian* \\ Paulo Henrique Costa Nascimento*
}

\section{Resumo}

Este texto apresenta uma revisão bibliográfica, visando analisar questões históricas e atuais relacionadas à formação, à função e às formas de provimento do diretor de escola e suas implicações na qualidade do ensino da escola pública, questionando transversalmente o papel dos pesquisadores da área e suas formas de estabelecer as relações entre a teoria e a prática. Assim, o texto é dividido em três partes: na primeira, apresentamos os sentidos construídos pela área da gestão educacional sobre os temas em destaque - gestão e qualidade - e identificados em nossos levantamentos e análises da produção do conhecimento; na segunda, propomo-nos a constituir os subsídios teórico-metodológicos que nos têm permitido a aproximação com a escola em novas bases epistemológicas, que são nossos sentidos em construção. Por fim, na terceira parte, relacionamos tais sentidos em construção com o que denominamos sentidos em construção pelas e nas escolas públicas municipais.

Palavras-chave: Democracia. Gestão da educação. Sentidos em construção.

\section{Abstract}

The text starts from a bibliographical review, aiming to analyze historical and current issues related to the formation, function and forms of provision of the school director and its implications on the quality of public school teaching, questioning transversally the role of researchers in the area and their forms of Establish relationships between theory and practice. Thus, the text is divided into three parts: in the first part, we bring to the reader the meanings built by the area of educational management on the main themes - management and quality identified in our surveys and analyzes of knowledge production. In the second, we propose to constitute the theoretical-methodological subsidies that allow us to approach school on new bases, which are our senses under construction. Finally, we dialogue these senses in construction with what we call senses under construction by and in municipal public schools.

Keywords: Democracy. Education management. Meanings under construction.

Recebido em: 17/03/2017 - Aprovado em: 31/05/2017

http://dx.doi.org/10.5335/rep.v24i2.7416

Doutora em Educação pela Universidade Estadual Paulista Júlio de Mesquita Filho, com pós-doutoramento na Universidade do Vale do Rio dos Sinos. Professora Assistente do Departamento de Administração e Supervisão Escolar e do Programa de Pós-Graduação em Educação da Unesp (Marília, SP). E-mail: graziela.maia@gmail.com

** Mestrando no Programa de Pós-Graduação em Educação na linha de Políticas Educacionais, Gestão de Sistemas e Organizações, Trabalho e Movimentos Sociais, da Faculdade de Filosofia e Ciências da Universidade Estadual Paulista Júlio de Mesquita Filho (Marília, SP). Membro integrante do Centro de Estudos e Pesquisas em Administração da Educação (Cepae). E-mail: paulo.hcnascimento@gmail.com 


\section{Introdução}

Este texto é escrito no momento em que nós, participantes do Centro de Estudos e Pesquisas em Administração da Educação (Cepae), transitamos de uma participação coletiva em pesquisa em rede do Observatório da Educação para a construção de uma nova pesquisa, com a participação de pesquisadores de iniciação científica, mestrado e doutorado.

Na realização da pesquisa em rede, ao discutirmos as relações teóricas e práticas entre os indicadores de desempenho, gestão e qualidade de ensino, identificamos que, no âmbito teórico, há críticas contundentes às diretrizes governamentais que atrelam qualidade à produção de índices e, também, às práticas escolares que reproduzem essas diretrizes; com a empiria, diagnosticamos que a escola, no que se refere à organização do trabalho pedagógico, vem se constituindo para o alcance de resultados, lançando mão de estratégias criativas. No entanto, pais, alunos, funcionários e professores, na maioria de nossas conversas, indicaram o quanto é complexo pensar a qualidade, não a reduzindo aos resultados mensuráveis. Nossas análises foram ao encontro do nosso referencial daquele momento, que, no âmbito da sociologia das organizações escolares, afirmava, entre tantos outros elementos, que a escola possui margem de autonomia relativa para reinventar as políticas e negociar com elas para a realização de suas expectativas (LIMA, 1998; NÓVOA, 1995). ${ }^{1}$

Tanto esta pesquisa quanto a que a antecedeu, em que analisamos questões históricas e atuais relacionadas à formação, à função e às formas de provimento do diretor de escola e suas implicações na qualidade de ensino da escola pública, ${ }^{2}$ permitiram-nos, de forma autocrítica, questionar nossa construção como pesquisadores e as formas de estabelecer as relações entre a teoria e a prática. Os resultados de nossas pesquisas concordam com os de Souza (2006), quando o autor destaca que há ênfase normativa nos trabalhos de pesquisa ao enfatizarem como a escola deve se organizar para ser democrática e ter um ensino de qualidade. Essas constatações nos permitiram pressupor que existem elementos constitutivos da teoria que a impedem de se autoavaliar, no sentido de possibilitar a invenção de novas formas de relacionar teoria e prática e avançar o conhecimento na área.

Encontramo-nos, portanto, diante de inúmeros desafios, sendo o principal a possibilidade de repensarmos a própria função da teoria e a forma pela qual ela é construída. Ou seja, se a teoria não tiver o teor prescritivo, como estabelecer relações entre a teoria e a prática?

Diante do exposto, nosso objetivo é analisar os sentidos que estão em construção na e pela escola sobre gestão e qualidade, cotejando-os com aqueles sentidos que identificamos nos discursos acadêmicos, na tentativa de buscar elementos que permitam visualizar a produção do conhecimento de outra forma, que não a prescritiva. 
Nesse sentido, trata-se de um exercício em que nos permitimos ter dúvidas sobre a nossa própria forma de pensar e nos inserimos na área da gestão educacional.

Para tal, procedemos à divisão do texto em três partes. Na primeira, trazemos ao leitor os sentidos construídos pela área da gestão educacional sobre gestão e qualidade identificados em nossos levantamentos e análises da produção do conhecimento. Na segunda, propomo-nos a constituir os subsídios teórico-metodológicos que nos têm permitido a aproximação com a escola em novas bases epistemológicas, que são nossos sentidos em construção. Por fim, na terceira parte, relacionamos tais sentidos em construção com o que denominamos sentidos em construção pelas e nas escolas públicas municipais. A tese que defendemos é a de que os sentidos em construção pelos integrantes das escolas públicas de diferentes sistemas municipais não se encerram em quadros teórico-metodológicos fechados, que também não se põem ao diálogo e à construção de novas balizas. Ou seja, defendemos a ideia de que precisamos buscar horizontes teórico-metodológicos que permitam a aproximação da escola em novas bases de construção do conhecimento científico (SOUSA SANTOS, 1999).

É preciso destacar que, ao sermos convidados a integrar este livro, que traz resultados de pesquisas cujos temas em destaque envolvem gestão democrática, formas de provimento do cargo do diretor e qualidade de ensino, permitimo-nos tomar como base empírica, que comporá a terceira parte deste texto, seis escolas públicas municipais de diferentes localidades do país, cuja especificidade que merece destaque é a forma de provimento, sendo duas com diretor eleito, duas com diretor concursado e duas com diretor indicado. Consideramos a importância dos respectivos contextos e dos elementos constitutivos de cada escola, mas, para o objetivo a que nos propusemos, eles não serão trabalhados. Para esta análise, consideramos entrevistas semiestruturadas com diferentes integrantes de cada escola, realizadas no percurso das pesquisas relatadas nesta introdução.

\section{Gestão e qualidade: sentidos construídos}

Concordando com Oliveira (2015), podemos dizer que os discursos sobre gestão e qualidade no âmbito acadêmico se assemelham por integrarem um campo discursivo composto por um conjunto de enunciados que seguem regras e normas historicamente determinadas pelos integrantes do próprio discurso. Sendo assim, o que dizemos sobre os temas academicamente "não foge às regras impostas pelo discurso que nos autorizam a proferir determinadas verdades e não outras" (OLIVEIRA, 2015, p. 107, grifo da autora). No entanto, seguindo o raciocínio da autora, embora muitos discursos tenham se constituído como verdades (muitas vezes irre- 
futáveis), consideramos que é possível um movimento autocrítico para sua consequente reinvenção.

Ao analisarmos a área da gestão escolar, identificamos sua constituição de forma polarizada, o que, conforme Russo (2004), caracteriza dois paradigmas opostos. A base teórica dos estudos até meados dos anos 1980 foi a teoria da administração empresarial, representavam tal vertente alguns autores clássicos da área (RIBEIRO, 1952; ALONSO, 1976; LOURENÇO FILHO, 1978). A abertura política e o processo de (re)democratização da sociedade permitiram que o referencial crítico fosse incorporado aos estudos de educação e à gestão escolar, que, de um caráter eminentemente técnico, passa a se constituir, nos escritos acadêmicos, como ato político a serviço da transformação social (ARROYO, 1983; PARO, 1986; FELIX, 1989).

Em ambos os paradigmas, a escola tem um papel importante a desempenhar: para o primeiro, cujas bases são as teorias da administração empresarial, a escola eficaz contribui com a formação de trabalhadores para o desenvolvimento econômico da sociedade e a conservação do status quo; para o segundo, cuja base é a teoria marxista, numa perspectiva histórico-crítica da educação, a escola pode contribuir, via instrumentalização dos sujeitos e desenvolvimento da consciência crítica, com a transformação da sociedade. Este paradigma considera, sobretudo, a especificidade da escola em relação a outras organizações e adota como subsídio a teoria da gestão democrática da escola pública, cujo centro é a oposição à semelhança entre administração empresarial e escolar, defendendo como elementos principais: eleição direta para diretores escolares pela comunidade, participação dos diferentes segmentos (pais, alunos, funcionários e professores) nas tomadas de decisão da escola, via órgãos colegiados e instituições auxiliares de ensino (participação direta e participação representativa) (LUCE; MEDEIROS, 2006).

Nossas pesquisas (NASCIMENTO, 2014; RUSSO; MAIA, 2009; MURCIA, 2015) identificaram que a mudança de paradigma também pressupôs uma nova perspectiva metodológica das pesquisas, que passam a ir para a escola a fim de buscar dados empíricos para suas análises. No entanto, com o respaldo da teoria da gestão democrática, fechada em conceitos e prescrições, as pesquisas não fogem à polarização (teoria da administração empresarial x teoria da gestão democrática) e não dão conta de constituir uma nova vertente, que supere tal dualidade. Referente a essa constatação, Souza (2006) contribui ao afirmar que a maioria das pesquisas mantêm um teor prescritivo e que um futuro democrático perspectivado por elas se tornou um "porvir" não vingado.

No que tange à qualidade da escola pública,a dualidade também se faz presente no discurso acadêmico e nas prescrições à escola.

Em meados dos anos 1990, momento em que se iniciava, no Brasil, uma afirmação dos princípios neoliberais e ocorria a posse de Fernando Henrique Cardoso 
como presidente (cujas principais diretrizes para a educação já foram demasiadamente analisadas por pesquisadores brasileiros), Singer (1996) profere um discurso na abertura da reunião bianual da Associação Nacional de Pesquisa e Pós-Graduação em Educação (Anped), posteriormente publicado na Revista Brasileira de Educação, em que destaca a presença de duas visões opostas de educação: a civil democrática e a produtivista. As próprias denominações permitem inferir a quem e como servem, não necessitando esclarecê-las, mas apenas chamar a atenção do leitor para a proximidade que elas mantêm com aquelas perspectivas de gestão que também constituem a dualidade.

Sanches (1997), na mesma ótica, mas em país diferente, indica a presença de duas posições extremas: uma posição racionalista, que tem na instrumentalidade a via para a qualidade e na objetividade a garantia da avaliação da qualidade; e uma posição inspirada na teoria crítica, que põe em causa os pressupostos da primeira. Para os adeptos da posição racionalista, um ensino de qualidade é dependente de bases científicas e pode ser determinado pelos resultados dos alunos em testes estandardizados. O procedimento conduz a duas implicações negativas para a organização e para o ensino: na organização, desenvolve-se um clima caracterizado por hostilidade e atitudes defensivas, pela ausência de espírito crítico e pelo isolamento; no ensino, a preocupação com a objetividade conduz a uma visão atomista do processo de ensino, na qual o conhecimento é divisível em partes e as questões do ensino são reguladas por preocupações de eficácia e eficiência. A outra visão de qualidade, a holística, apresenta preocupações intelectuais, de desenvolvimento do espírito crítico e da autonomia mediante incentivo à participação dos alunos no processo de aprendizagem.

Nosso percurso de pesquisa, ao longo do desenvolvimento dos projetos anunciados na introdução, permite-nos dizer que os diferentes artigos, teses, dissertações, livros e capítulos circunscrevem-se em tal dualidade, reafirmando o caráter progressista da teoria crítica e de sua própria perspectiva. Inclusive, tanto Singer (1996) quanto Russo (2004) provocam seus leitores para que a teoria ganhe força e/ ou seja tão audaz quanto a sua adversária, para que possa transformar a realidade das escolas públicas, marcadas pela reprodução de atividades burocráticas e pela conservação da sociedade como tal. Essa assertiva pode ser ilustrada com as duas citações seguintes, cujas bases nos provocam, na próxima seção, a buscar subsídios teóricos que permitam uma aproximação da escola de outra forma:

O grande debate sobre a crise educacional pode dar frutos se os que defendem a tradição democrática e igualitária conseguirem passar à ofensiva, com propostas tão audazes e imaginosas quanto seus oponentes. E, sobretudo, se conseguirem implementar essas propostas, abandonando uma postura meramente ofensiva de conquistas pretéritas (SINGER, 1996, p. 11, grifo nosso). 
[...] no âmbito da teoria, há um movimento que se desloca do paradigma empresarial para o da especificidade da escola. Quando esse deslocamento produzir um maior peso específico para o paradigma da especificidade da escola, certamente passará a influir de maneira mais decisiva na prática, que, assim, indicará a tendência de esse paradigma se tornar dominante (RUSSO, 2004, p. 40, grifo nosso).

Articulando os dois temas - gestão e qualidade - nos sentidos construídos pelo discurso acadêmico, Oliveira (2015) realizou um levantamento sistemático de artigos publicados em periódicos qualificados e analisou 50 deles com o objetivo de identificar as concepções de qualidade da educação escolar presentes. A autora destaca que o "peso maior recai sobre os textos que consideram a gestão democrática $(29,4 \%)$, as práticas pedagógicas $(25,4 \%)$ e as estruturas físicas escolares $(27,4 \%)$ os indicadores de qualidade de maior expressão", e endossa nossos apontamentos anteriores ao constatar que "[...] até mesmo os estudos que se situam em uma posição crítica com relação às políticas de avaliação da qualidade escolar, acabam por reproduzir um discurso prescritivo muito semelhante àqueles presentes nos documentos oficiais [...]" (OLIVEIRA, 2015, p. 112). Nesse sentido, sugerem que a vivência da gestão democrática pode ser elemento importante para a transformação da realidade escolar, sendo indicador crucial na busca de resultados, que não sejam apenas aqueles encontrados nos testes externos.

Do exposto, podemos constatar que, embora prevaleça em nosso discurso acadêmico a presença de referencial crítico na análise do contexto político, social e também escolar, em sua especificidade, temos conservado uma forma de produzir conhecimento semelhante ao referencial que é criticado, ou seja, mantemos uma relação externa à escola, dizendo o que ela não é e o que deveria ser, o que ela não faz e deveria fazer e, por isso, que temos um conhecimento que ela não tem. Tais constatações nos desafiaram à construção de novos sentidos para nos aproximarmos da escola, em novas bases epistemológicas.

\section{Escola: nossos sentidos em construção}

As pesquisas do nosso grupo se inserem no movimento que privilegia a escola como centro do debate e da produção do conhecimento em gestão educacional, desde 2005, caminhando com os conflitos e os desafios indicados anteriormente no que tange, principalmente, às relações entre teoria e prática. Nossas discussões se basearam, até pouco tempo antes da redação deste texto, em três perspectivas teórico-metodológicas, reconhecidas por nós como: a) a sociologia das organizações escolares ou a escola como organização educativa; b) a instituição escolar; e c) os estudos nos/dos/com os cotidianos escolares. A seguir, relatamos, sucintamente, as 
bases de tais perspectivas para indicar seus limites quando nos encontramos com as escolas, seus sujeitos, suas práticas, seus discursos e suas realizações.

A perspectiva da escola como organização educativa consolidou-se com o intercâmbio entre pesquisadores brasileiros e portugueses quando estes passam a privilegiar o nível meso de abordagem - a escola - e, indicando os limites das perspectivas anteriores intituladas macro (Estado) e micro abordagens (sala de aula), vislumbram o estudo a partir da escola como aquele que possibilita "cruzar a reflexão científica com a inovação educacional” (NÓVOA, 1995, p. 24). O livro organizado por Barroso (1996) traz comunicações de um congresso realizado em Portugal, que teve como foco a escola como objeto de estudos, posteriormente, o livro de Lima (1998) cunha a sociologia das organizações escolares cujas bases teóricas pressupõem privilegiar as ações dos atores escolares, como se organizam, reproduzem e produzem regras, ou seja, a "ação organizada", em detrimento do "plano de ação para as organizações", que vêm externamente para os sujeitos escolares cumprirem.

Atendendo ao convite feito por Lima (1998), Silva Jr. e Ferretti (2004) escrevem um livro com o foco na necessidade de compreender os impactos das reformas educacionais dos anos 1990 na prática escolar. Diferentemente da perspectiva anterior, os autores contemplam e destacam a face institucional da escola como aquela que atribui sua densidade histórica, com as marcas do Estado moderno. Respaldando-se em perspectiva histórico-crítica, Silva Jr. e Ferretti (2004) defendem que a prática escolar traz a potência para a formação do ser social para seu desenvolvimento superior, atendendo à transformação da sociedade, mas, ao contrário, ela pode se fazer como prática alienada e alienante.

Apesar de se constituírem com subsídios teóricos diferentes, as duas perspectivas anunciadas apresentam semelhanças e podem, inclusive, ser complementares. O principal aspecto que nos permite essa afirmação é o fato de ambas conservarem a dualidade na aproximação com a escola: na primeira, há, entre outras oposições, o plano de ação e a ação, a fidelidade e a infidelidade dos atores; na segunda, há a prática alienada que forma o sujeito em si alienado e a prática que forma o sujeito para si, com carecimentos superiores, o ordenamento jurídico-burocrático, as políticas com suas diretrizes e a organização de cada instituição escolar. Dessa forma, a prática - a escola - pode ser potente se não seguir à risca as diretrizes da política, mas, contraditoriamente, ela deve seguir as diretrizes teóricas de quem tece críticas a ambas (a escola e a política).

Em nosso percurso de pesquisa, a terceira perspectiva se efetivou quando buscamos um contraponto com as anteriores e nos deparamos com os estudos de pesquisadores da área do currículo, que se caracterizam pelos estudos nos/dos/com os 
cotidianos (ALVES, 1991). Nessa perspectiva, os pesquisadores precisam identificar as heterogeneidades, a pluralidade de táticas e astúcias (CERTEAU, 1998) e os diversos movimentos de criação presentes nas práticas cotidianas, por meio do diálogo entre várias lógicas de pensamento. Para o desenvolvimento desses estudos, Alves (1991) indica que é necessário: diálogo com outras formas de ver a realidade, com atenção aos detalhes e aos modos de fazer dos "praticantes", de modo a reafirmar o cotidiano como espaço/tempo de saber, criação e grande diversidade; novo modo de olhar para as teorias, com todos os seus limites, principalmente reconhecendo que não representam verdades absolutas; ampliação das fontes de pesquisa, incorporando novos registros do cotidiano, como fotos, memórias, arquivos, narrativas; novas maneiras de registrar a pesquisa, que cumpram o objetivo de chegar até os "praticantes" do cotidiano.

$\mathrm{O}$ que podemos aprender com essas experiências de pesquisa com a trajetória do conhecimento em gestão educacional, como pesquisadores em construção? Não se trata de enfatizar a política em detrimento do cotidiano e tampouco enfatizar o cotidiano em detrimento da política, justamente porque o problema está na própria ênfase enquanto princípio na prática de pesquisa. Ora, quando se descobriu a ênfase no Estado e a desvalorização do cotidiano nas práticas de pesquisa, buscou-se a ênfase no cotidiano para desvalorização do Estado, mas não se abandonou a ênfase em alguma das instâncias, ou seja, não se abandonou a prática de pesquisar com duas instâncias, de modo que uma delas seja desvalorizada para a outra se impor.

É nítido, neste momento, que podemos apontar duas maneiras de abordar a política e o cotidiano no conhecimento em gestão educacional: como instância e como princípio de pesquisa. Assim, podemos também apontar o principal problema que persiste nas práticas de pesquisa na área que não permite valorizar o cotidiano em sua plenitude sem colocá-lo como algo utópico, ideológico e anticientífico. É que ele foi abordado como instância e não como princípio de pesquisa, ou seja, foi lugar para se aplicar uma ciência, e não como um saber que contribui para a construção do próprio conhecimento em gestão escolar. Mesmo quando Canário (1996), por exemplo, destaca que a escola não "emerge" como objeto de estudo, não é "descoberta" como objeto de estudo, mas a "construímos" como objeto de estudo - uma vez que, segundo ele, objetos sociais são construídos como objetos científicos -, ela foi construída como um local onde realizamos nossas pesquisas, uma instância.

Segundo Gallo e Figueiredo, a ênfase está associada a um modo maior ou majoritário de fazer pesquisa e funciona "[...] como estado de poder e de dominação, ela pressupõe a sistematização e o esquematismo, luta pra ser modelo e para manter-se modelo" (2015, p. 38). Por outro lado, o cotidiano como princípio de pesquisa está associado a um modo menor ou minoritário de fazer pesquisa, "[...] é a potência de criação, que se contrapõe a um estabelecido que já não pode criar" 
(2015, p. 38). Portanto, o que está em jogo no cotidiano como princípio de pesquisa é poder resistir ao modelo e, principalmente, criar novos modos de se fazer pesquisa e se relacionar com o cotidiano da escola.

O maior e o menor não se distinguem pelo tamanho ou pela importância, eles “[...] não são proposições contrárias e opostas, mas co-funcionantes, ou seja, cada um se move em função de suas preocupações diferenciadas que são realizáveis, no mais das vezes, em consonância transversal" (GALLO; FIGUEIREDO 2015, p. 26). Portanto, não é por meio da imposição de um modelo e da desvalorização do outro que se pode pensar com o cotidiano, mas, sim, permitindo a convivência dos vários modos de pensar, pois mesmo o modelo que impõe precisa do seu oposto para impor. No caso do cotidiano, ele precisa do seu oposto para resistir e criar.

Vimos com Alves (1991) e Certeau (1998) que o cotidiano age por meio de múltiplos agentes, heterogeneidades, diversidades, criações, adaptações e bricolagens, portanto, nesta prática de pesquisa, valoriza-se essa multiplicidade ao invés de dar ênfase a algum elemento. Desse modo, no cotidiano da escola, coexistem elementos da política, do Estado, de pesquisa, dos saberes pedagógicos, dos costumes, da religião, da cultura, além de variados elementos que o pesquisador poderia valorizar, que poderiam fazer parte da construção do saber ao invés de serem excluídos por ele.

Ao invés de ir à escola dizer o que ela faz de errado ou o que ela deveria fazer de acordo com um modelo possível ou uma teoria pronta, o pesquisador poderia buscar nas falas, nos costumes, nos gestos de alunos, professores, pais, diretores e funcionários elementos que mostrem os limites do conhecimento, as possíveis falhas e, principalmente, os elementos que são excluídos, para que não se trate mais de um modelo pronto, mas, sim, uma coisa viva, que se constrói e se modifica cotidianamente. E o contrário também é possível. O cotidiano escolar pode utilizar os resultados de pesquisa para aprimorar suas práticas e construir novas formas de se fazer a educação e entender as possíveis falhas e os limites novos, que aparecem no cotidiano: a ciência como um "novo senso comum" (SOUSA SANTOS, 1999). Nossa tentativa, a seguir, é exatamente essa.

\section{Sentidos em construção em escolas públicas municipais}

Como foi identificada, no levantamento e na análise da literatura, a oposição entre dois modelos de gestão, servindo aos seus respectivos modelos de qualidade da educação escolar, pensamos que encontraríamos esses modelos com facilidade nos percursos que fizemos em diferentes cotidianos durante os anos de pesquisa. Mas não foi isso que aconteceu. A riqueza e a complexidade do cotidiano com suas falas, realizações, conflitos e questionamentos são impressionantes. 
Com o objetivo de analisar os sentidos sobre gestão e qualidade construídos por diferentes integrantes de escolas públicas municipais, tomamos como critérios de escolha para a redação deste texto seis escolas que tiveram salto significativo no Índice de Desenvolvimento da Educação Básica (Ideb), sendo duas com diretores eleitos, duas com diretores concursados e duas com diretores indicados pelo poder político local.

A primeira escolha - salto no Ideb - foi feita porque, como demonstram resultados de pesquisas já realizadas (OLIVEIRA, 2015), existem representações compartilhadas de que escola de qualidade é aquela com bom resultado nas avaliações externas e com alto índice. Por mais que os discursos acadêmicos questionem essa assertiva, a pesquisa citada mostrou que eles também compartilham dela. Nossa intenção era a de compreender os sentidos atribuídos pelos diferentes integrantes sobre o tema, fugindo da necessidade de encontrar uma verdade ou um fundamento fixo para a qualidade.

A segunda escolha - diferentes formas de provimento - foi feita porque, dentro da polarização anunciada anteriormente no campo da gestão educacional, existem algumas verdades compartilhadas - sentidos construídos -, que são: diretores concursados tendem a ser tecnocratas e prepostos do Estado; a participação na escola cujos integrantes elegeram seu diretor tende a se efetivar porque a comunidade participa desde sua eleição; etc.

Com um roteiro prévio, porém flexível, gravamos entrevistas com dois integrantes de cada segmento de cada escola. ${ }^{3}$ Com o conjunto das entrevistas transcritas de forma literal, procedemos à leitura sistemática com o objetivo de encontrar os sentidos e, como a intenção não foi dizer se eles estavam certos ou errados, observar se eles se afastam ou não de um "modelo" de legislação e/ou de teoria, deixamos que as falas nos mostrassem aspectos a serem evidenciados, tendo como norte a hipótese anunciada na introdução.

Os excertos de falas e as suas análises apresentados a seguir nos permitem concordar com as ideias de Mendonça e Rodrigues (2014), quando afirmam, tendo como referência Derrida (2002), numa hipótese pós-clássica, que o “[...] fundamento último é impossível não pelo excesso de possibilidades empíricas verificáveis, mas justamente pela inexistência de um fundamento definitivo como tal" (MENDONÇA; RODRIGUES, 2014, p. 43). Tomando o cotidiano como princípio de pesquisa, encontramos o "excesso de possibilidades empíricas", que nos permite dizer que não existe um sentido de democracia dado pela academia e/ou por diretrizes governamentais, mas existem, sim, inúmeras possibilidades e porvires na multiplicidade de práticas cotidianas.

Encontramos as escolas com vida, o que pressupõe, como primeiro aspecto a ser analisado, a própria autocrítica dos sujeitos que lá estão nos concedendo entrevistas, fato difícil de encontrar em nosso meio acadêmico. 
As diretoras concursadas foram professoras por mais de cinco anos antes de assumirem o cargo, porém, não na escola em que iniciaram tal atividade profissional. Uma delas recordou como e quando chegou à escola e os problemas que encontrou: não tinha equipe de gestão, equipe constituída por professores rotativos, "crianças com nível de aprendizagem assim, muito ruim, repetentes, alunos na quarta série que não sabiam ler, muito ruim, muito ruim mesmo", "mães que vinham bater em professor", etc. A decisão tomada por essa diretora foi a de centralizar o processo pedagógico. No momento da entrevista, ela constrói respostas longas, fazendo uma autoavaliação e revendo algumas práticas: "eu era bastante autoritária no começo [...] eu me refiz desta autoridade um autoritarismo mesmo, principalmente com os professores, funcionários, eu era muito autoritária, muito centralizadora mesmo" (Diretora concursada, grifo nosso). Ao mesmo tempo em que ela aponta a centralização, faz uma crítica ao seu papel como diretora, dizendo: "eu fazia errado, não da forma como tinha que ser feito, [...] os dois primeiros anos foram, nossa, um fiasco [...] acho que agora vou ter que mudar mais uma vez"; e destaca que, desde que chegou à escola, foram construídos a Associação de Pais e Mestres (APM) e o Conselho de Escola, com a participação dos diferentes segmentos. Para ela, mesmo não sabendo muito bem, mas "correndo atrás de livros" e estudo individual, "[...] de alguma forma, a gente trouxe a representatividade dos pais, mesmo sem saber muito bem o que significava isso [...] então aproximamos, sim, a comunidade escolar da escola" (Diretora concursada).

A fala dessa diretora é muito rica para nós, pois evidencia o momento de aprendizado que é a concessão da entrevista. Quando vamos à escola solicitar a realização de uma pesquisa, ouvimos de quem nos recebe que eles não têm retorno, que o pesquisador utiliza a escola para fazer críticas e não "devolve" seus resultados. Gostaríamos de destacar que ambos - pesquisador e entrevistado - aprendem e produzem conhecimento com o encontro. Neste caso, em específico, a entrevistada pôde se avaliar, de forma espontânea, modificando conceitos e revendo práticas. Os entrevistadores puderam compreender que essa prática se efetiva com o diálogo, com a troca, e não com a imposição de verdades.

Isso não nos impede de desenvolver pesquisas críticas, no entanto, altera nosso entendimento sobre ela, porque passamos a entender que "a razão que ela critica não pode ser a mesma que pensa, constrói e legitima aquilo que é criticável" (SOUSA SANTOS, 1999, p. 204-205), sendo assim, encontramos linhas de fuga para que o dito "conhecimento-emancipação" não se converta em "conhecimento-regulação" (SOUSA SANTOS, 1999, p. 205). Com Sousa Santos, defendemos que não é possível estabelecer a "ordem sobre o caos", mas a pesquisa pode desenvolver análise crítica pressupondo que "a existência não esgota as possibilidades da existência 
e que, portanto, há alternativas susceptíveis de superar o que é criticável no que existe" (SOUSA SANTOS, 1999, p. 197).

Em relação às atividades do diretor de escola, os diretores eleitos e concursados enfatizaram o "controle de tudo" e o "querer saber de tudo" como sendo os principais aspectos de sua função e de sua sobrecarga de trabalho:

[...] enquanto diretora eu tenho que saber de tudo o que acontece (Diretora concursada).

[...] faço tudo, cobra-se tudo. No meu caso você tem que saber do pedagógico, do administrativo, da estrutura do prédio, de toda a documentação, tem que dar conta de tudo e é uma sobrecarga muito grande (Diretora concursada 2).

[...] passa tudo pela gestão, tem que ter assim aquele olhar bem atento de estar acompanhando tudo, estar verificando tudo; o principal da gestão é se preocupar com toda a escola, não só com o administrativo, tem que se preocupar com o pedagógico, se preocupar com tudo, tem que dar conta de tudo (Diretora eleita).

[...] tem que saber mais do que o professor, tem que ter o olhar de forma, ele é professor, mas ele tem que saber como ajudar (Diretor eleito).

Uma das diretoras indicadas relatou que o momento em que assumiu a direção da escola era bastante delicado, porque a diretora que havia saído sofrera processo judicial e a escola tinha um reconhecimento negativo pela comunidade, com profissionais ditos muito agressivos com as crianças. Então, por essa razão, sua principal atividade foi:

[...] conquistar a confiança de todos e fazer com que cada um se responsabilizasse por aquilo que tinha que fazer [...] essa conscientização, essa humanização é o que mais busco fazer, que eu apanho, porque a impressão que eu tenho é que as pessoas não sabem lidar com a autonomia (Diretora indicada).

No grupo de diretores com o qual trabalhamos, os sentidos atribuídos pelos profissionais não são muito diferentes entre os eleitos e os concursados, mas, no caso da diretora indicada, ela nos mostrou um sentido particular, próprio de seu contexto e que foge às considerações negativas que lemos e construímos sobre diretor indicado. Perguntamos: por que o diretor eleito tem esta necessidade de controle de tudo? Por que não foi evidenciada, em sua fala, a necessidade de diálogo constante com a comunidade, o trabalho de articulação de demandas? Por que o diretor indicado não sobrevalorizou a necessidade de cumprir as demandas da secretaria? Ao contrário, essa diretora enfatizou, por exemplo, que precisou conquistar a comunidade, fazer uma pós-graduação com vínculo com a universidade pública para buscar a construção de um projeto coletivo, que trouxesse a comunidade para dentro da escola, e que, muitas vezes, por ser indicada, os professores a enfrentam e vão direto à secretaria, mas que, como tem a comunidade e o respeito, não tem 
medo de enfrentar essas situações. Interessante destacar que os diretores indicados têm compreensão dos aspectos políticos que permeiam sua atividade e avaliam criticamente isso:

[...] precisava de mais apoio da secretaria, amparo, material pedagógico, professor bom, pois nossa realidade não é fácil. Mas isto eu não tenho, acho que dizem: é cargo de confiança, não tem direito, não tem poder. Não sei onde isso vai parar. O que gosto mesmo é da sala de aula. Mas, mesmo assim, eu faço os enfrentamentos (Diretora indicada).

O conjunto de aspectos referentes à função do diretor permite, mais uma vez, que nos afastemos de fundamentos referentes à relação entre provimento e gestão da escola. O cotidiano escolar, com suas falas, opiniões e especificidades, se faz como "[...] espaço-tempo de uma educação menor, região de fronteiras e de proliferação das diferenças, é o espaço possível da criação da autonomia como linhas de fuga" (GALLO; FIGUEIREDO, 2015, p. 49).

Quando perguntamos sobre o que o diretor precisa estudar/conhecer para ocupar tal função/cargo, encontramos fortes semelhanças nas respostas dos diferentes profissionais das escolas (diretores e professores), ao dizerem, diretamente e sem demora: "legislação". Eles enfatizam a necessidade de se amparar em leis e de ter conhecimento sobre elas no cotidiano para resolver os conflitos que o permeiam, em seguida, destacam conhecimento de sala de aula e da comunidade.

No entanto, de forma surpreendente, encontramos respostas potentes de mudança e de fuga às verdades pré-estabelecidas de mães, pais, alunos e, principalmente, funcionários. As mães e os pais entrevistados indicaram que o diretor precisa: "entender de aluno" (Mãe de aluno, escola com diretor indicado); "saber como o aluno aprende" (Mãe de aluno, escola com diretor concursado); "trabalhar em prol da comunidade" (Mãe de aluno, escola com diretor eleito); "estudar muito como se trabalha com crianças, acho que é toda essa área da educação infantil, né?” (Mãe de aluno, escola com diretor eleito).

Os funcionários entrevistados, nas diferentes escolas, não se sentem parte integrante do fazer pedagógico, quando dizem, por exemplo, “[...] não sei, porque meu trabalho não tá lá, na sala de aula" (funcionário de escola com diretor eleito) ou "[...] a gente tem reuniões, podemos participar porque essa direção quis implantar isso de que somos todos iguais, mas a gente só participa se acha que vai ajudar alguma coisa, mas como elas são pedagógicas, a gente nem fica" (funcionário de escola com diretor eleito). No entanto, apresentaram, nos diferentes temas discutidos, rica perspectiva pedagógica e política, por exemplo, quando destacaram os problemas com as avaliações externas: "[...] eu fico triste quando você vê dois, três anos seguidos o Enem... vaza informação eu não sei o que é que tem, o que acontece, eles, que são o meio pensante no país, não conseguem fazer uma prova que 
não contenha erro, é ridículo" (funcionário de escola com diretor concursado); “[...] a prova pode até existir porque é uma forma dos professores pensarem, os alunos, diretora, de partir de algo para melhorar, para mudar, mas tem que ser sério" (funcionário de escola com diretor concursado); "[...] a gente tem autonomia e não tem, direto a diretora tem que mandar memorando, pedir, cumprir coisas da Secretaria” (funcionário de escola com diretor eleito).

Duas categorias merecem destaque direto em nosso trabalho, para concluirmos: a participação na escola e a qualidade de ensino. Sobre a participação, os diretores destacam a dificuldade de trazer os pais para participar da escola, inclusive, nas duas escolas em que foram eleitos. Em todas elas, foi destaque, nas entrevistas com os diferentes integrantes, o canal aberto que a comunidade tem com a escola, no sentido de ouvir, "dar opinião", poder procurá-la a qualquer momento. Contudo, em apenas duas instituições, os entrevistados disseram existir o Conselho de Escola, mas, na maioria, é confundido com o Conselho de Classe e/ou desenvolve as mesmas funções da Associação de Pais e Mestres (APM) ou do Centro de Pais e Mestres (CPM), terminologias diferentes que designam uma instituição auxiliar de ensino que recebe, pensa, decide e destina a verba da escola, a qual deveria ser aprovada pelo órgão colegiado (Conselho de Escola).

Alguns pais confundem participação com contribuir financeiramente com a escola: "[...] os pais dessa escola poderiam participar mais sim, eles poderiam dar mais dinheiro para melhorar a escola" (Mãe de aluno, escola com diretor eleito); “[...] quando os pais são chamados eles vêm para ajudar nas festas" (Mãe de aluno, escola com diretor concursado). Alguns professores destacam que aluno não pode participar, porque: "nós tínhamos o Grêmio Estudantil, mas não deu certo. Eles queriam mandar muito, o que se elege presidente quer mandar na escola. Já é característico deles ter chefões, e na escola não seria diferente" (professor, escola com diretor eleito).

No entanto, apesar de a participação não se apresentar como está determinada no discurso acadêmico e/ou na legislação, ${ }^{4}$ encontramos práticas discursivas que potencializam a democracia e que não estão necessariamente relacionadas à forma de provimento do diretor. Em uma das escolas em que o diretor é indicado, houve trabalho específico de sua parte para buscar um coletivo que propusesse um trabalho de aproximação com a comunidade e, apesar das dificuldades históricas dessa escola, em todas as entrevistas, apareceu a participação como sendo um elemento importante para a recuperação da credibilidade do trabalho pedagógico perante a comunidade.

Uma mãe entrevistada nessa escola relatou: “APM e Conselho não são a mesma coisa, mas são dois caminhos que levam a um só não é? Eu já fiz parte dos dois, o sentido é um só, a linguagem é uma só, as críticas, as reclamações que vêm sempre 
têm o lado positivo, nós discutimos" (Mãe de aluno, escola com diretor indicado). Um funcionário da mesma escola diz que participou de várias reuniões do conselho e da APM e que os pais vêm e participam: "[...] a gente vai até buscar em casa e nos recebem bem. [...] tudo tem conversa, a gente tem abertura para chegar nas pessoas [...]". Os professores das escolas em que o diretor foi concursado destacam que as reuniões coletivas, denominadas de Hora de Estudo (HE), "não são para passar informações, são de estudo e para tomar decisões, geralmente, todo o grupo participar, a diretora chama a gente, é tudo aberto" (Professora, escola com diretor concursado).

Alguns relatos também demonstram a aproximação da escola com a família: "quando chamamos a família vem, são raras aquelas que não vêm" (Diretor eleito); "fazemos reuniões em horários diferentes para poder contar com a presença dos pais" (Diretor eleito); "reunião dos pais não vinham ninguém, hoje, a gente consegue ver a mudança, a família vem, participa, apoia, a gente chama e tem retorno" (Professora, escola com diretor eleito).

Finalmente, quando questionados sobre se consideram a escola de qualidade e o porquê, os entrevistados dos diferentes segmentos nos ensinam o quão complexo é falar sobre isso, destacando o tema de forma contextualizada. Nenhum entrevistado lembrou, de forma direta, das avaliações externas e da classificação da escola, merecendo destaque os relatos a seguir: "[...] nesta escola, falar de qualidade é falar de tudo que fazemos e com todos os problemas de lidamos" (Diretor indicado); "O Ideb aumentou, mas ficamos surpresos porque não esperávamos, temos problemas sérios para resolver na escola" (Professora, escola com diretor concursado); “[...] a prova que os alunos fazem não diz nada porque o importante é a gente ver estes alunos lendo e escrevendo e, às vezes, a escola tira nota boa e o aluno não sabe ler e escrever" (Mãe de aluno, escola com diretor concursado); “[...] a escola aumentou o Ideb, mas o importante é o conjunto, não a nota" (Funcionário, escola com diretor concursado); "[...] no nosso mundo, o que a gente consegue com o aluno é a qualidade" (Professora, escola com diretor indicado); “[...] a escola é de qualidade por tudo que estamos fazendo, formar leva tempo, formar pessoas, conscientizar é diferente de ensinar, formar é trabalhoso... desde 2000 quanta coisa essa escola já conseguiu" (Funcionário, escola com diretor eleito).

\section{Algumas considerações}

Depois desses anos de trabalho e de vivência no cotidiano da escola, seria possível sair da mesma maneira que se entrou? Seria possível fazer pesquisa da mesma maneira? Será que as pessoas desses contextos cotidianos não sabem o que fazem, ideologizadas por um mercado edificante? Será que não lutam por algo? 
Para as duas últimas questões, não sabemos a resposta e nem buscamos resolvê-las, pois não queremos descobrir a origem dos problemas relacionados às pessoas da escola. Não buscamos culpar os déficits da aplicação do modelo de gestão de qualidade em suas práticas cotidianas, em sua suposta falta de consciência ou esclarecimento e/ou, finalmente, em sua suposta falta de comprometimento com a transformação social. Não esperamos que tudo se transforme, exceto nossas convicções e nossas práticas. Não criticamos tudo, exceto a nós mesmos. Ao contrário, a crítica que se faz ao cotidiano é voltada ao pesquisador e às suas ferramentas de análise. A cada passo dado dentro da escola, a cada resposta concedida nas entrevistas, assistimos aos dois modelos teóricos avermelharem-se de vergonha por não enxergarem, como o cotidiano, tantas coisas que existem nas práticas da gestão de uma escola. Entendemos, dessa forma, que a maneira de se fazer pesquisa possui seus déficits e limites em enxergar os mais variados comportamentos e atitudes que o diretor pode ter, como vimos em nossas vivências, que não estão amarrados ou enraizados nos modelos de gestão e nem na maneira pela qual o diretor ocupa seu lugar dentro da escola.

Poderiam dizer que: estas questões estão relacionadas ao campo da psicologia, e ela carece de crítica; que estas questões são tão filosóficas que não atingem a materialidade ou a concretude das relações sociais; ou que tais questões estão relacionadas aos problemas culturais, que relativizam tudo, e isso é anticientífico. O que vemos é que, além de esse contexto descentralizar o conhecimento em gestão em relação aos seus modelos, ele descentraliza também seus objetos, de maneira que ele não consegue resolver todas as questões que extrapolam seu viés analítico. Isso o obriga a conviver com a multidisciplinaridade, outros conhecimentos, que ameaçam seu ego totalizante e universal e seu modelo, que não se realiza e não permite que a diferença e outras visões de mundo existam.

Parece que não resolvemos, dentro do conhecimento acadêmico, nossos próprios problemas de prática de pesquisa e queremos dizer às escolas o que deveriam fazer para resolver os seus. Essas vivencias têm saberes que podem contribuir para a pulverização desses modelos do conhecimento em gestão, mas também para a construção de outros, que se pulverizarão, e para mudarmos nossa relação com as escolas: "eu sei, tenho a solução para seus problemas".

Com todos os elementos que trouxemos para a discussão, podemos afirmar que os sentidos nas escolas públicas não se fecham e, também, não permitem que as encerremos em modelos fundados em verdades. Há múltiplos sentidos e práticas em construção, e nossas teorias, se levadas de forma prescritiva, podem até considerar a escola como objeto de estudo, mas não conseguirão trabalhar o cotidiano escolar como "dobra da escola, seu dentro (educação maior, aparelho de Estado, utopia) e 
seu fora (educação menor, máquina de guerra, heterotopia)" (GALLO; FIGUEIREDO, 2015, p. 49), que é "regido pelas leis deste Estado maior que diz sobre suas configurações e funcionamentos, mas que também desenha outras experiências micropolíticas escapando-resistindo ao instituído" (GALLO; FIGUEIREDO, 2015, p. 45).

\section{Notas}

1 Pesquisas desenvolvidas no âmbito do projeto: Nascimento (2014); Oliveira (2015); Jesus (2013); Souza (2014).

2 Publicações referentes a esta pesquisa podem ser lidas em: Abdian, Hojas e Oliveira (2012); Abdian, Oliveira e Jesus (2013).

3 Em todas as entrevistas, perguntamos sobre: tempo que integram a escola; se gostam da escola e o porquê; como a escola se organiza; seus principais problemas; o que o diretor faz; se conhecem o Ideb e o que acham dele; se consideram a escola de qualidade e o porquê.

4 Assim como falamos anteriormente, os discursos acadêmicos tendem a se basear na legislação para abordar a gestão democrática, sendo assim, seguem o modelo contido na Lei de Diretrizes e Bases da Educação Nacional (Lei no 9.394/1996), que deveria ser regulamentada por lei específica de cada sistema de ensino: participação dos profissionais na elaboração do projeto pedagógico da escola, participação dos pais e comunidade em conselhos escolares e/ou equivalentes.

\section{Referências}

ABDIAN, G. Z.; OLIVEIRA, M. E. N.; JESUS, G. Função do diretor na escola pública paulista: mudanças e permanências. Educação e Realidade, Porto Alegre, v. 38, p. 977-998, 2013.

ABDIAN, G. Z.; HOJAS, V. F.; OLIVEIRA, M. E. Formação, função e formas de provimento do cargo do gestor escolar: as diretrizes da política educacional e o desenvolvimento teórico da administração escolar. Educação Temática Digital, Campinas, v. 14, n. 1, p. 399-419, jan./jun. 2012.

ALVES, A. J. O planejamento de pesquisas qualitativas em educação. Cadernos de Pesquisa, São Paulo, v. 77, p. 53-61, maio 1991.

ALONSO, M. O papel do diretor na administração escolar. São Paulo: Difel, 1976.

ARROYO, M. A administração da educação é um problema político. Revista Brasileira de Administração da Educação, Porto Alegre, v. 1, n. 1, p. 122-129, 1983.

BARROSO, J. (Org.). O estudo da escola. Porto: Porto Editora, 1996.

CANÁRIO, R. Os estudos sobre a escola: problemas e perspectivas. In BARROSO, J. (Org). $O$ estudo da escola. Porto: Porto, 1996.

CERTEAU, M. A invenção do cotidiano: artes de fazer. 3. ed. Petrópolis: Vozes, 1998.

DERRIDA, J. A escritura e a diferença. 3. ed. São Paulo: Perspectiva, 2002.

FELIX, M. F. C. Administração escolar. Problema educativo ou empresarial? São Paulo: Cortez, 1989. 
GALLO, S.; FIGUEIREDO, G. M. Entre maioridade e menoridade: as regiões de fronteira no cotidiano escolar. Aprender - Cadernos de Filosofia e Psicologia da Educação, Vitória da Conquista, ano IX, n. 14, p. 25-51, 2015.

JESUS, G. de. Cultura organizacional e avaliação em larga escala: faces e interfaces a partir da análise de escolas públicas municipais. 139f. Dissertação (Mestrado em Educação) - Faculdade de Filosofia e Ciências, Universidade Estadual Paulista, Marília, 2013.

LIMA, L. C. A escola como organização educativa. 4. ed. São Paulo: Cortez, 1998.

LOURENÇO FILHO, M. B. Organização e administração escolar: curso básico. 7. ed. Rio de Janeiro: Instituto de Estudos e Pesquisas educacionais Anísio Teixeira, 1976.

LUCE, M. B.; MEDEIROS, I. L. P. de. Gestão democrática da escola pública: práticas e vivências. Porto Alegre: Editora Ufrgs, 2006.

MAIA, G. Z. A. As publicações da Anpae e a trajetória do conhecimento em administração da educação no Brasil. Revista Brasileira de Política e Administração da Educação, Porto Alegre, v. 24, n. 1, p. 31-50, jan./abr. 2008.

MENDONÇA, D. de; RODRIGUES, L. P. Do estruturalismo ao pós-estruturalismo: entre fundamentar e desfundamentar. In: (Org.). Pós-estruturalismo e teoria do discurso: em torno de Ernesto Laclau. 2. ed. Porto Alegre: EdiPUCRS, 2014. p. 22-59.

MURCIA, A. B. Gestão democrática, conselho de escola e qualidade do ensino: a produção da Revista Brasileira de Política e Administração da Educação (2000-2010). Trabalho de Conclusão de Curso (Graduação em Pedagogia) - Faculdade de Filosofia e Ciências, Universidade Estadual Paulista, Marília, 2015.

NASCIMENTO, P. H. C. Administração escolar no Brasil e sociedade de controle: o paradigma multidimensional e a teoria das multiplicidades. Trabalho de Conclusão de Curso (Graduação em Pedagogia) - Faculdade de Filosofia e Ciências, Universidade Estadual Paulista, Marília, 2014.

NÓVOA, A. (Org.). As organizações escolares em análise. 2. ed. Lisboa: Publicações Dom Quixote, 1995.

OLIVEIRA, M. E. Qualidade da educação escolar: discursos, práticas e representações sociais. 289f. Tese (Doutorado em Educação) - Faculdade de Filosofia e Ciências, Universidade Estadual Paulista, Marília, 2015.

PARO, V. H. Administração escolar: introdução crítica. São Paulo: Cortez: Autores Associados, 1986.

RIBEIRO, J. Q. Ensaio de uma teoria da administração escolar. São Paulo: FFCL - USP, 1952. (Boletim 158).

RUSSO, M. H. Escola e paradigmas de gestão. Eccos, São Paulo, v. 6, n. 1, p. 25-42, 2004.

RUSSO, D. A.; MAIA, G. Z. A. A escola como objeto de estudo da ciência da educação no Brasil (1990-2005). Revista Brasileira de Política e Administração da Educação, Porto Alegre, v. 25, n. 3, p. 523-541, set./dez. 2009. 
SANCHES, M. F. C. Para um ensino de qualidade: perspectiva organizacional. Inovação - Revista do Instituto de Inovação Educacional, Portugal, Universidade de Lisboa, v. 10, n. 2 e 3, p. 165-194, 1997.

SILVA JR., J. dos R.; FERRETTI, C. J. O institucional, a organização e a cultura da escola. São Paulo: Xamã, 2004.

SINGER, P. Poder, política e educação. Revista Brasileira de Educação, Rio de Janeiro, n. 1, p. 1-14, jan./abr. 1996.

SOUSA SANTOS, B. de. Por que é tão difícil construir teoria crítica? Revista Crítica de Ciências Sociais, Coimbra - Portugal, n. 54, p. 197-215, 1999.

SOUZA, A. R. de. Perfil da gestão escolar no Brasil. Tese (Doutorado Educação) - Pontifícia Universidade Católica de São Paulo, São Paulo, 2006.

SOUZA, T. B. de. Avaliação em larga escala, gestão e qualidade de ensino em duas escolas públicas municipais. 157f. Dissertação (Mestrado em Educação) - Faculdade de Filosofia e Ciências, Universidade Estadual Paulista, Marília, 2014. 